\title{
Transcriptional analysis of the multiple Sry genes and developmental program at the onset of testis differentiation in the rat
}

\author{
Jeremy W. Prokop ${ }^{1,2,3}$, Surya B. Chhetri ${ }^{3,4}$, J. Edward van Veen ${ }^{5}$, Xuqi Chen ${ }^{5}$, Adam C. Underwood ${ }^{1,6}$, Katie Uhl ${ }^{1}$, \\ Melinda R. Dwinell ${ }^{7}$, Aron M. Geurts ${ }^{7}$, Stephanie M. Correa ${ }^{5}$ and Arthur P. Arnold ${ }^{5^{*}}$ (D)
}

\begin{abstract}
Background: The commonly used laboratory rat, Rattus norvegicus, is unique in having multiple Sry gene copies found on the $Y$ chromosome, with different copies encoding amino acid variations that influence the resulting protein function. It is not clear which Sry genes are expressed at the onset of testis differentiation or how their expression correlates with that of other genes in testis-determination pathways.
\end{abstract}

Methods: Here, two independent E11-E14 developmental RNAseq datasets show that multiple Sry genes are expressed at E12-E13.

Results: The identified copies expressed during testis initiation include Sry4A, Sry1, and Sry3C, which are conserved in every strain of Rattus norvegicus with genomes sequenced to date.

Conclusions: This work represents a first step in defining the complex environment of rat testis differentiation that can open the door for generating sex reversal model systems using embryo manipulation techniques that have been available in the mouse but not the rat.

Keywords: Sry, Testis determination, Sex determination, Rattus norvegicus, RNAseq, Transcriptome, Gonadal ridge, Embryo

\section{Introduction}

Differentiation of the testes in most metatherian and eutherian mammals is initiated by SRY, encoded by the Y chromosome [1-3]. Knockout and transgenic experiments in mice demonstrate that Sry is critical for the development of the testes [4]. SRY expression in somatic cells of the undifferentiated gonadal ridge activates a cascade of testis-differentiating genes including Sox9 $[5,6]$. In humans, SRY is expressed also in germ cells [7]. In humans and rodents, SRY is also expressed throughout

\footnotetext{
* Correspondence: arnold@ucla.edu

${ }^{5}$ Department of Integrative Biology \& Physiology, Laboratory of

Neuroendocrinology of the Brain Research Institute, University of California, 610 Charles Young Drive South, Los Angeles, CA 90095, USA

Full list of author information is available at the end of the article
}

adulthood in non-gonadal tissues such as the brain and adrenals [8, 9]. In rats, the Sry gene has been duplicated through gene conversion at transposable elements on the Y chromosome [10]. Common laboratory strains of rats have at least 11 copies of Sry genes (Sry1, Sry2, Sry3, Sry3A, Sry3B, Sry3BI, Sry3BII, Sry3C, Sry4, Sry4A, nonHMG Sry) [10-12], some of which are expressed in many non-gonadal tissues. Amino acid variants among different Sry proteins alter biological function [10, 13]. Two unusual variants include nonHMG-Sry and Sry2. The former encodes a protein lacking the HMG domain common to all SOX family proteins, required for DNA binding and SOX protein function. The Sry2 gene is located within the gene coding region of $K d m 5 d$ and shows ubiquitous expression in male tissues, yet contains a mutation that

(C) The Author(s). 2020 Open Access This article is licensed under a Creative Commons Attribution 4.0 International License, which permits use, sharing, adaptation, distribution and reproduction in any medium or format, as long as you give appropriate credit to the original author(s) and the source, provide a link to the Creative Commons licence, and indicate if changes were made. The images or other third party material in this article are included in the article's Creative Commons licence, unless indicated otherwise in a credit line to the material. If material is not included in the article's Creative Commons licence and your intended use is not permitted by statutory regulation or exceeds the permitted use, you will need to obtain permission directly from the copyright holder. To view a copy of this licence, visit http://creativecommons.org/licenses/by/4.0/ The Creative Commons Public Domain Dedication waiver (http://creativecommons.org/publicdomain/zero/1.0/) applies to the data made available in this article, unless otherwise stated in a credit line to the data. 
reduces nuclear localization of the protein $(\sim 50 \%$ retained cytoplasmic localization) and alters transcriptional potential [10]. Analysis of numerous RNAseq datasets shows that diverse Sry genes other than Sry 2 are expressed in a pattern overlapping with that of human $S R Y$ expression [13].

A major unresolved question in laboratory rats is which Sry gene(s) cause(s) testis differentiation. One copy may be sufficient, with others being redundant (or not), or several Sry copies of varying function may all be required. Here, we sequenced RNA from rat gonads at the time of testis differentiation to determine which Sry genes are expressed when the testis-determining factor is active. Three Sry genes (Sry1, Sry4A, and Sry3C), other than Sry2, were found to be expressed at the highest levels at E13, the time of testis differentiation, a result that narrows down the Sry genes that likely act as the testisdifferentiating factor. This is the first report of multiple Sry genes potentially contributing to testis differentiation in a mammal. The results represent an important step forward in understanding testis differentiation in one of the most highly studied animal model systems used in biomedical research. This information will be essential for understanding the function of the different Sry genes in gonadal development and for engineering rat models that genetically separate the effects of sex chromosomes and circulating hormones on sexual differentiation, similar to the Four Core Genotypes mouse model [14, 15].

\section{Methods}

\section{Animals}

Timed pregnant Sprague Dawley CD1 rats were obtained from Charles River (San Diego, CA, USA). In experiment 1 , pregnant females were euthanized at embryonic day $11,12,13$, and 14 (E0 = day of seminal plug). Tissue was collected from the urogenital ridge, including gonadal anlage and adjacent tissue, as described below. This analysis provided a preliminary assessment of gene expression across embryonic ages before and after onset of testis differentiation, with one or two independent pooled samples per age. E11 and 14 fetuses were staged by limb morphology [16]. E12 and E13 fetuses were precisely staged by counting the number of tail somites (ts) [17]. In each E11 fetus, a single urogenital complex was collected from both sides, including both urogenital ridges and both pronephroi $(n=2$ pools). For the E12 (10-12 ts) fetus $(n=1$ pool) and E13 (21-22 ts) fetuses ( $n=2$ pools), two urogenital ridges, which include the gonadal ridge and mesonephros, were collected. At E14, two gonads, dissected away from the mesonephroi, were collected and pooled ( $n=1$ pool). In experiment 2 , we used the preliminary data from experiment 1 to select one specific age (E13) with the highest expression of Sry and dissected only gonadal tissue, with much higher sampling $(n=5$ independent samples from different fetuses), to focus on expression at the time of putative onset of testis differentiation. All 5 samples were gonad pairs, dissected away from the mesonephroi, from E13 (21 ts) XY fetuses. All samples were sexed by PCR for X-Y copies of Med14 (primers F: CCTCCA GACCCTATTACCAA, R: ATCACTGTCAAGGTTGCT $\mathrm{TC}$ ), which produces a $560 \mathrm{bp}$ PCR product in XX females and $560 \mathrm{bp}$ and $172 \mathrm{bp}$ products in $\mathrm{XY}$ males.

\section{RNAseq}

For experiment 1 (BioSample SAMN13930124), RNA was extracted from urogenital ridge of E11 and E12, the genital ridge/mesonephros of E13, and testes of E14 fetuses using Trizol (Invitrogen, Carlsbad, CA, USA) and treated with RNase-free DNase (Promega, Madison, USA) to remove possible genomic DNA contamination. RNA quality was checked using an Agilent TapeStation. RNAseq was processed at the HudsonAlpha Institute for Biotechnology (HAIB) Genomic Services Laboratory using PolyA capture and sequenced on Illumina HiSeq v4 generating 50 bp paired end reads (Table 1).

For experiment 2 (BioSample SAMN13930125), sequencing was performed on libraries prepared from previously snap-frozen gonads. RNA was isolated using the column-based Qiagen RNeasy Micro kit. RNA integrity was assayed on an Agilent TapeStation. RNA Integrity number (RIN) values for all samples ranged from 8.5 to 9.2. The Nugen Ovation RNA-Seq system V2 was used for reverse transcription of cDNA, and the Nugen Ovation Ultralow system V2 was used to prepare sequencing-ready libraries. Libraries were quantified using Qubit DNA high-sensitivity reagents, and library quality control was performed on an Agilent TapeStation using a D5000 high-sensitivity DNA tape. Sequencing was performed in a single lane of paired-end $(2 \times$ 75) Illumina NextSeq 500 using v2 reagents, and later demultiplexed. Reads for all experiments are available online from the SRA as listed in Table 1 and are found in the NCBI BioProject PRJNA603367.

\section{Bioinformatics}

Each of the RNAseq datasets was quantified using Salmon tools [18] against the Rattus norvegicus Ensembl transcript build 96. Sample analysis was performed using Network Analyst [19] with comparisons being made with DESeq2 [20] with cutoff $\log 2$ fold change values of $>2$ or $<-2$ and an adjusted $p$ value $<0.01$. Gene networks and Gene Ontology (GO) enrichment were performed using STRING [21], such that we clustered genes elevated at each day that are connected to various biological and molecular pathways. Sry mapped reads were extracted using Burrows-Wheeler aligner (BWA) [22] against the Sry1 gene (AY157669.1). Single nucleotide markers for each of the Sry genes were used from 
Table 1 RNAseq samples for NCBI BioProject PRJNA603367

\begin{tabular}{|c|c|c|c|c|c|c|}
\hline Name & Day & Experiment number & NCBI SRA accession & Location of RNAseq & \# Spots & GC \% \\
\hline E11 & E11 & 1 & SRR10971979 & HAIB & $76,755,285$ & 52.53 \\
\hline E11_2 & E11 & 1 & SRR10971978 & HAIB & $82,683,942$ & 52.70 \\
\hline E12 & E12 & 1 & SRR10971976 & HAIB & $66,920,760$ & 51.84 \\
\hline E13 & E13 & 1 & SRR10971975 & HAIB & $89,604,541$ & 50.80 \\
\hline E13_2 & E13 & 1 & SRR10971974 & HAIB & $67,669,568$ & 50.52 \\
\hline E14 & E14 & 1 & SRR10971973 & HAIB & $67,718,710$ & 52.19 \\
\hline $21 \mathrm{ts} \_1$ & E13 & 2 & SRR10971972 & UCLA & $26,540,107$ & 43.48 \\
\hline 21 ts_2 & E13 & 2 & SRR10971971 & UCLA & $23,227,742$ & 43.60 \\
\hline 21ts_3 & E13 & 2 & SRR10971970 & UCLA & $27,134,789$ & 44.22 \\
\hline 21 ts_4 & E13 & 2 & SRR10971969 & UCLA & $25,802,203$ & 43.58 \\
\hline $21 \mathrm{ts} \_5$ & E13 & 2 & SRR10971977 & UCLA & $26,166,729$ & 43.94 \\
\hline
\end{tabular}

our previous publication [13] (Fig 2b). Read depth for each of the bases was extracted from the BWA alignment of all mapped RNAseq datasets in addition to each individual analysis using UGENE [23], followed by averaging the percent of each base at every position. Marker spots for each of the Sry genes were averaged to determine the relative percent composition of each Sry gene, which was then multiplied by the transcripts mapped per million reads sequenced (TPM) to determine composition of Sry at each time point.

\section{Results}

Using RNAseq, in experiment 1, we surveyed gene expression in samples of $\mathrm{XY}$ male urogenital ridge across embryonic days 11-14, using low sample coverage at each embryonic day, to give a preliminary assessment of the timing of expression of Sry and other genes known to be involved in testis differentiation in other mammalian species. Based on those results, E13 was identified as the time with highest expression of Sry. In experiment 2, we performed well-powered analysis of gene expression on E13, only in the testis itself, without contamination of adjacent non-gonadal tissues. Using variant mapping between the different copies of Sry, it was then possible to determine the percent of total Sry each copy makes up, which was used to normalize total Sry mapping into each specific copy.

\section{Differentially expressed genes}

The principal components analysis of RNASeq samples shows clustering based on principal component (PC) 1 and 2, with different clustering of E11 and E12/13 samples (experiment 1, Fig. 1a); PC1 stratifying the two different experiments; and PC2 stratifying day of embryonic development. The samples from E13 (21 ts) of experiment 2 cluster differently from those of experiment 1 (Fig. 1a). This is likely due to the difference in tissues sampled in the two experiments. Previous studies have shown testis differentiation begins at E12 in rats [24]. Preliminary gene analysis comparing E11 $(n=2)$ and E12/E13 samples $(n=3)$ from experiment 1 using DESeq2 (adj $p<0.01)$ revealed a significant enrichment, based on gene ontology to the entire genome, for genes involved in gonadal development (12 genes: Amhr2, Bcl2, Cga, Cyp1b1, Inhbb, Lhx9, Mgst1, NrOb1, Nr5a1, Ren, Sohlh2, Wt1, FDR = 0.0015), kidney development (9 genes: Agtr2, Egr1, Hrsp12, Hspa8, Nphs2, Ren, Sdc4, Sulf1, Wt1, FDR = 0.023), and core histones (11 genes: ENSRNOG00000034127, Hist1h2aa, Hist1h2an, Hist1h2bd, Hist1h2bf, Hist1h2bk, Hist1h2bo, Hist1h3c, Hist2h2ab, LOC690131, rCG_23123, FDR $=7.8 \times 10^{-7}$ ). Because of the differential clustering of E12/13 relative to either E11 or E14, we plotted two comparisons, E12/ 13 vs E11 ( $x$-axis) and E12/13 vs E14 ( $y$-axis), identifying multiple genes that, like Sry, have increased expression on E12/13 relative to either E11 or E14 (Fig. 1b, $p<$ 0.001 , group 1); genes that are higher in all days except E11 (Fig. 1b, $p<0.001$, group 2); and genes that are lower in E12/13 vs. either E11 or E14 (Fig. 1b, $p<0.05$, group 3). Although the measurement of these genes is preliminary based on the low sample size, there were numerous genes known to be activated in other studies at testis differentiation that are observed with the expected time course in Fig. 1c, suggesting that E13 was the optimal age for further analysis with a higher sample size in experiment 2 . The absolute values of gene expression in experiment 1 and several of the genes potentially elevated at E12/13 are subject to replication in future studies because of the low sample size at each age.

The measurement of gene expression exclusively from gonadal tissue at E13 (21 ts) in experiment 2 suggests that many genes unique to E12/13 groups are from the genital ridge and not from the mesonephros (Fig. 1b, colored dots). The expression of several markers for sexual differentiation of the gonads at each of the days of rat development fall within these groups that begin to 


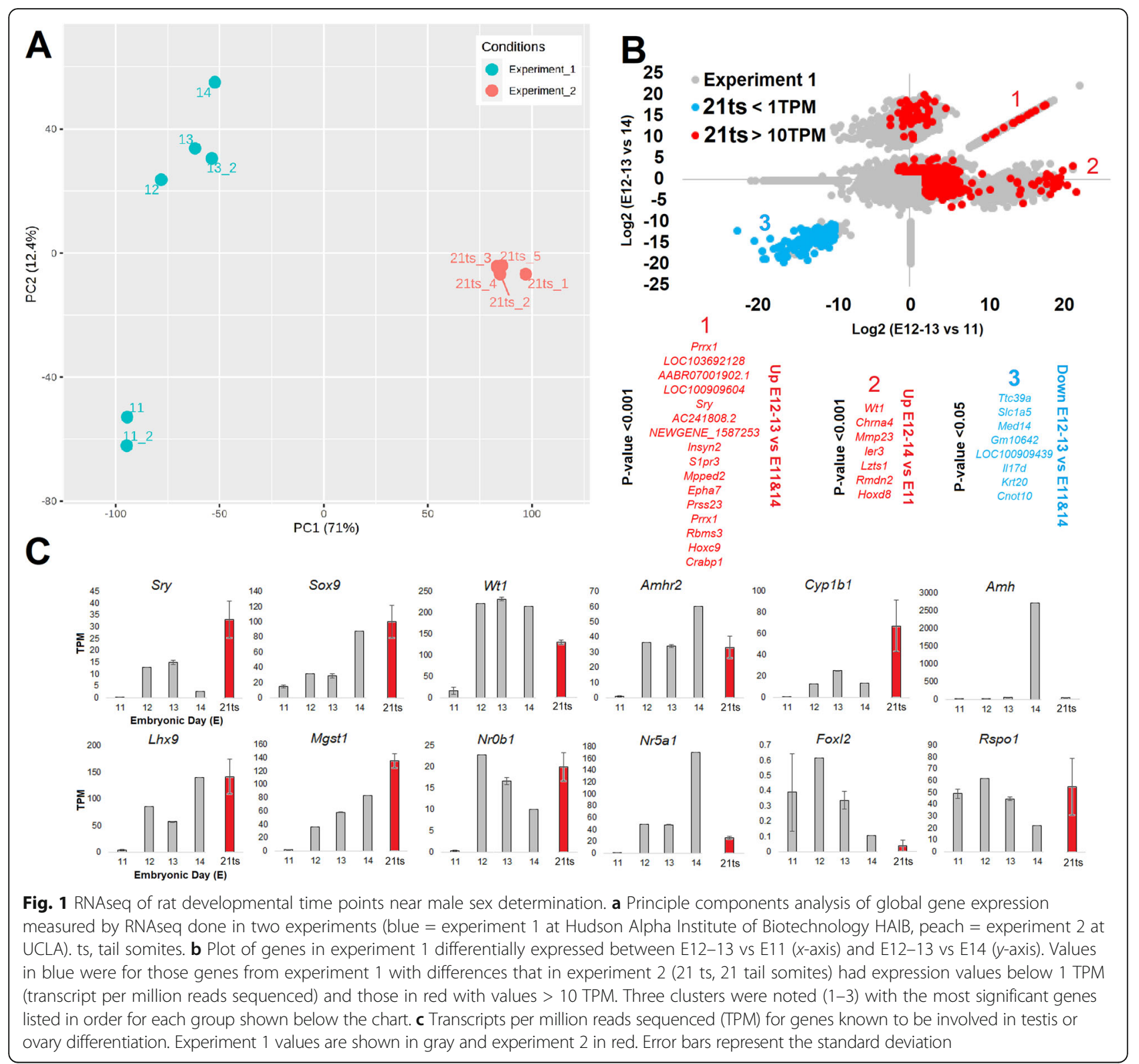

increase in expression at E12 of experiment 1 (Sry, Sox9, Wt1, Amhr2, Cyp1b1, Lhx9, Mgst1, NrOb1, Nr5a1; Fig. 1c), whereas experiment 2 (21 ts) further confirms the presence of these markers. Amh increased expression later, at E14. Ovary markers Foxl2 and Rspo1 appeared to be downregulated by E14 (Fig. 1c). Our bulk dissection of developmental days (experiment 1) confirms that E13 corresponds to the beginning of testis determination. Fine dissections of 21 ts embryos with an $n$ of 5 validate the presence of Sry, allowing for repeated independent assessments of Sry copies at testis differentiation.

\section{Expression of different Sry genes}

Expression of Sry increased at E12 and E13, correlated with initiation of testis differentiation, suggesting that these RNAseq runs have the power to segregate copies of different Sry genes by sequence during this period. We began by measuring the read depth for Sry in each of the RNAseq files (Fig. 2a). A total of 16 variants were identified to differentiate the Sry genes (Fig. 2b), 10 of which were found within the protein-coding region (Fig. 2c). Compiling all reads of Sry genes in all RNAseq runs, the average depth at any site within the gene is 563 reads, with $>150$ read coverage at amino acids 9-779 (Fig. 2d), where 1 is the first base of the transcript. Using the compiled data, 25 locations have variation of bases within the reads, with all of our markers showing variation (Fig. 2e) and high coverage (197-1007 reads). We removed markers that fall below 150 read depth, removing many variants that show up on the 3 ' end of the transcript. With the 

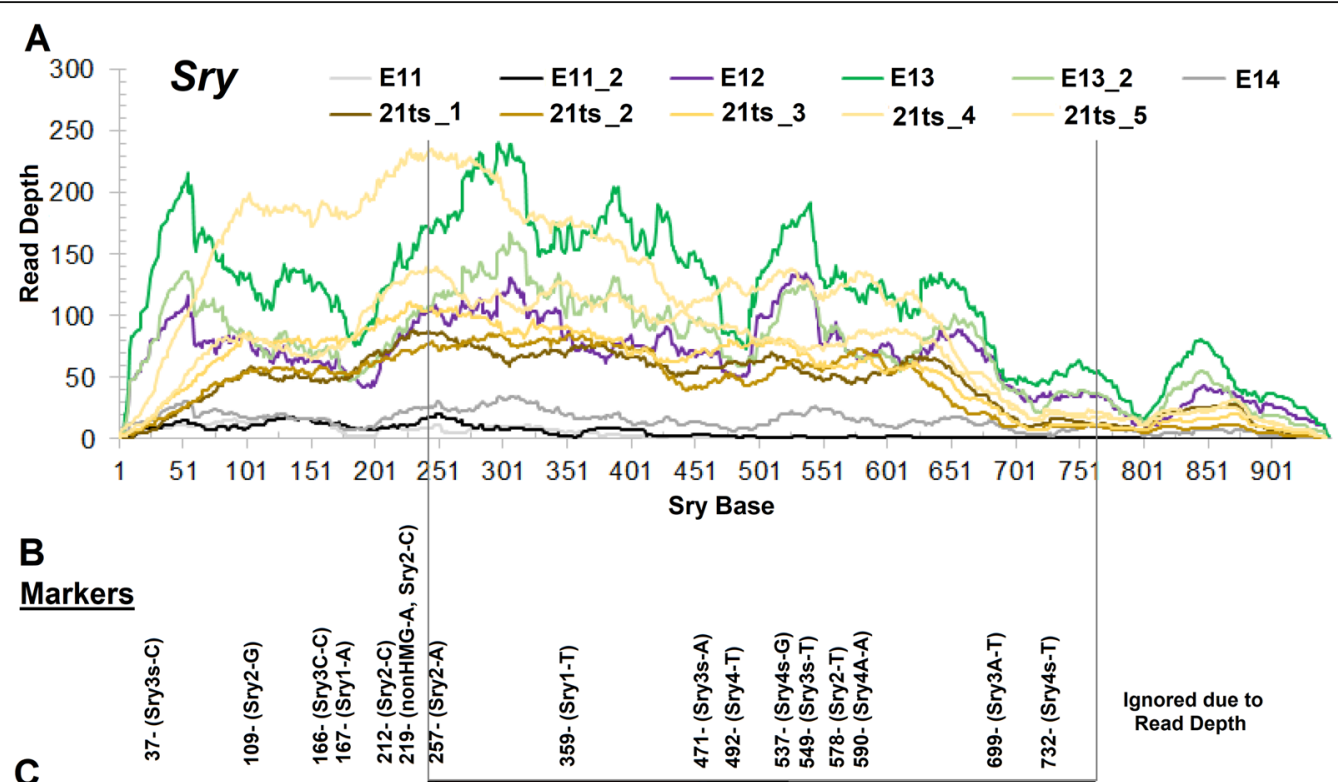

C

Protein

D

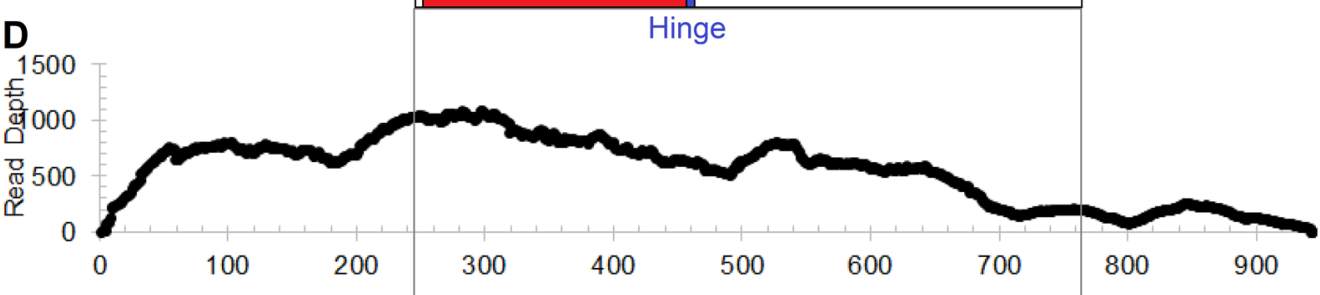

E

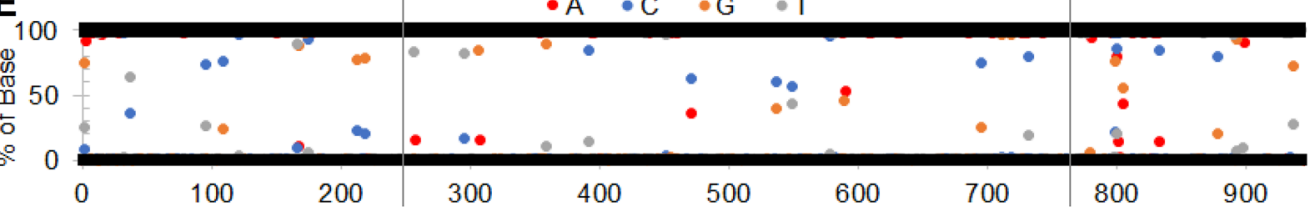

$\mathbf{F}$

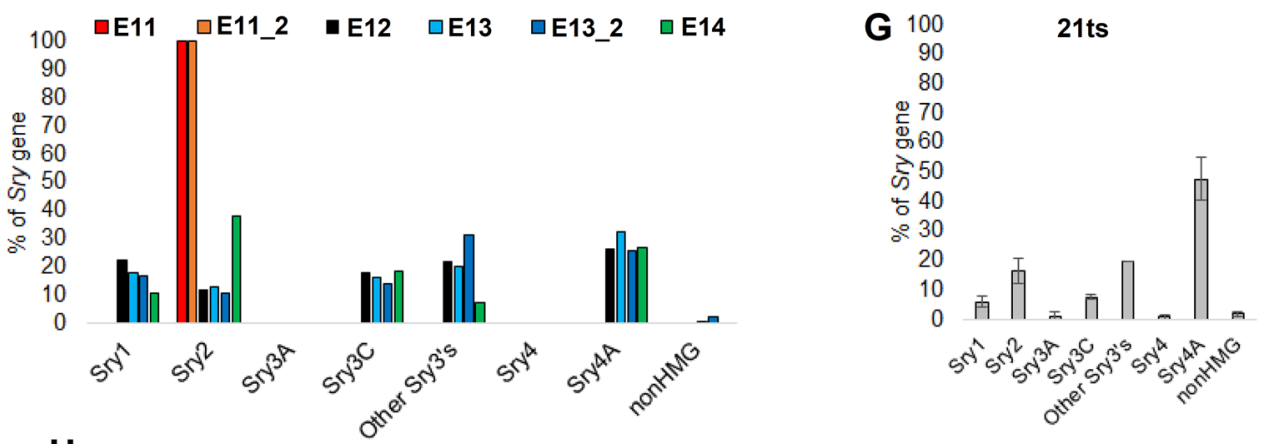

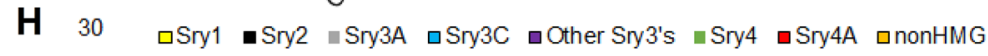

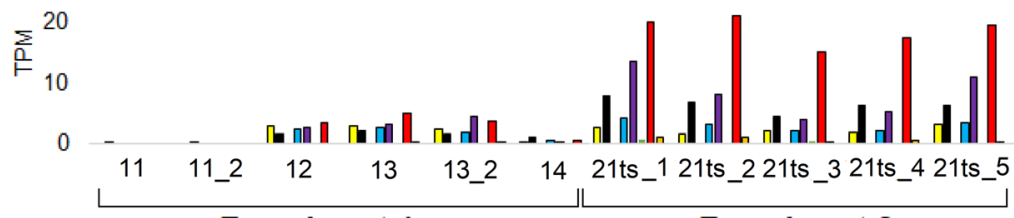

Experiment 1

Experiment 2

Fig. 2 (See legend on next page.) 
(See figure on previous page.)

Fig. 2 Sry gene mapping in RNAseq. a-e All panels of Sry mapped data are aligned relative to the transcript positions with the coding region marked by gray lines. a Depth of reads aligned to Sry for each sample representing different embryonic stages. $\mathbf{b}$ Single nucleotide variants along the Sry genes used for determining Sry copies expressed. c SRY protein corresponding to regions of the gene aligned to panels $\mathbf{a}$ and $\mathbf{b}$. $\mathbf{d}$ Total read mapping over the Sry gene from all datasets. e The percent of each base ( $y$-axis) at positions along the Sry gene (x-axis). Bases with values between 0 and 100 are those with variants in the different Sry genes seen in reads generated from all experiments. Values of 0 and 100 are shown as black line with any positions outside of these shown. Bases are listed as $A=r e d, C=$ blue, $G=$ orange, and $T=$ gray. $\mathbf{f}, \mathbf{g}$ The percent of each Sry gene using markers from panel $\mathbf{b}$ for the various days of experiment 1 (f) and analysis of multiple E12 (21 ts, tail somites) embryos in experiment 2 (g) with standard deviation shown as error bars. The high percentage expression of Sry2 at E11, despite its low abundance (h), results from the absence of expression of other Sry genes at E11. $\mathbf{h}$ Conversion of total Sry TPM using percent of each Sry gene to determine the individual Sry gene TPMs. In experiment 1, two samples were measured on E11 and 13. In experiment 2, 5 samples were measured from fetuses with 21 tail somites

markers, we calculated the percent of Sry reads that map to each of the genes. At E11 (experiment 1), prior to testis differentiation, the ubiquitously expressed Sry 2 represented $100 \%$ of reads (Fig. 2f), even though absolute numbers of reads was low at this time point (Fig. 2a gray and black). Over the period E12-E14 (experiment 1), we identified Sry1, Sry3C, Sry4A, and "other Sry3s" (transcripts for which reads did not allow further assignment to specific Sry3 genes) (Fig. 2f). Analysis of data from E13 in experiment 2 confirmed that $S r y 4 A$ was expressed at the highest level, together with other Sry3s, Sry2, Sry3C, and Sry1 (Fig. 2g). Very low levels of expression on all days were found for Sry3A, Sry4, and the nonHMG Sry, suggesting these genes have minimal involvement in testis differentiation. Normalizing the globally mapped TPM values on each RNAseq dataset for Sry using the percent composition of each copy shows a relatively high value of Sry4A, other Sry3s, Sry3C, and Sry1 starting at E12, continuing at E13, and decreasing at E14 (Fig. 2h).

\section{Discussion}

The present findings suggest that Sry genes are expressed in a narrow window at the onset of rat testis development, beginning at E12/E13 and declining on E14. Sry 4 A may not decrease in expression by E14. This result supports the idea that E12 is the first day of testis differentiation in Sprague Dawley rats. The onset of Sry expression appears to mirror that previously shown in mice and rats and supports the idea that Sry expression in rat gonadal ridge may not be needed for testis differentiation after its brief peak on E12/E13. Because Sry2 is expressed in testis before and after E12/13 and in nearly all male non-gonadal tissues in adult [13], we discount its possible role in causing testis differentiation, especially because it lacks an efficient nuclear translocation signal. The results further support the idea that the top candidate testis-differentiating gene is $\operatorname{Sry} 4 \mathrm{~A}$, because it is expressed at E13 higher than any other single Sry gene, and in some individuals higher than all other Sry genes combined (Fig. 2h). Sryl and Sry3C are also expressed at significant levels. Thus, Sry $4 A$, Sry3C, and Sry1 are the top candidates for transgenic manipulation to cause sex reversal. These results suggest that Sry3A, Sry4, and the nonHMG Sry are not significantly expressed and therefore are not involved in testis differentiation. The data do not discriminate between Sry expression in the Sertoli cell somatic lineage vs. germline cells and do not resolve if several Sry genes are required or redundant for the testis-differentiation cascade. SRY expression is found in human germ cells [7] and in rat testis [13]. Our previous work suggests that Sry3s are the primary transcripts in adult rat testis, and here, we suggest that Sry4A is expressed more at the time or testis differentiation.

The Sry genes in rodents are known to differ from human $S R Y$ in that they lack the $\mathrm{N}$-terminal region that contains phosphorylation signal sites suggested to be involved in SRY activation [25]. Instead, the rodent Sry genes have an extended $\mathrm{C}$-terminal polyglutamine tract that is essential for testis differentiation and required for the activation of $\operatorname{Sox} 9$ [26]. This region contains a high concentration of CAG coding glutamine codons with an additional high level of "FHDH" motifs. Interestingly, the rat Sry genes ( $\sim 25$ amino acids) have a shorter polyglutamine tract than mouse ( 240 amino acids), with the different Sry genes having variation in the length and compositions of the tract [10] suggesting continued drift of the region following duplication of genes. This unstable CAG region has allowed for rapid evolution of Sry genes in rodents, with suggestions that the length of the region determines SRY activation potential [27]. Thus, mouse Sry has a higher activation potential with the larger polyglutamine tract than rat Sry. Our data presented here suggest the interesting hypothesis that unlike human with the activation potential of the $\mathrm{N}$-terminus or the mouse long polyglutamine tract, rat has evolved the use of multiple copies of the Sry genes to reach activation levels required to initiate testis differentiation. Further studies are required to test this hypothesis.

This RNAseq work also extends our group's previous mapping all possible Sry copies found on the rat Ychromosome. Here, we have added studies of the Sprague Dawley strain, but find no newly identified variants that would suggest unmapped copies in this strain. Our 
previous work has identified Sry1, Sry $4 A$, and Sry3C, reported here as potential genes causing testis differentiation, to be present in the SHR, WKY, FHH, FHL, ACI, SR, SS, and F344 rat strains [13], further supporting the conservation of these copies in nearly all common rat strains used in research. From the sequenced SHR Ychromosome of rat [12], we know that all but the Sry2 copy of Sry genes in rat have several thousand base pairs of shared sequence $5^{\prime}$ and $3^{\prime}$ to the gene [10]. From amino acid comparisons, we also know that $\operatorname{Sry} 1$ most resembles human and mouse $S r y, S r y 4 A$ contains a variant L98V that has little alteration of SRY transcriptional function [10], and Sry3C contains a P76T variant that slightly impacts the protein's transcriptional potential [28]. However, all of these copies have been shown to be functional SRY proteins, unlike the ubiquitously expressed Sry 2 copy that has variants $\mathrm{H} 4 \mathrm{Q}$ and $\mathrm{R} 21 \mathrm{H}$ known to impact protein nuclear localization and a shortening of the polyglutamine tract that decreases activation [10]. The identification of Sry2 in E11 confirms our analysis of Sry in RNAseq that identified Sry 2 in all analyzed male samples [13], suggesting a ubiquitous expression that is in line with being unable to initiate testis differentiation.

\section{Conclusion}

Our findings agree with previous evidence that Sry genes other than $S r y 2$ regulate testis differentiation, and identify Sry1, Sry $4 A$, and Sry3C as top candidates for the testis-differentiating gene(s). All of these are conserved in all common laboratory rat strains.

\section{Acknowledgements}

Thanks to Haley Hrncir for assistance.

\section{Authors' contributions}

JP, MD, AG, SMC, and AA designed the project. SBC, AU, KU, and EV analyzed the data. XC assisted in tissue collection, isolated RNA, and performed genotyping. SMC collected tissues. JP, EV, XC, SC, and AA drafted the manuscript, and all authors edited the manuscript. The authors read and approved the final manuscript.

\section{Funding}

Funding for this work was from NIH R21OD026560 (to APA, AMG, and MRD) and K01ES025435 (to JWP), Michigan State University, and a pilot grant from the David Geffen School of Medicine at UCLA.

\section{Availability of data and materials}

All RNAseq data can be obtained from NCBI under BioProject PRJNA603367. The SRA-deposited RNAseq FASTQ files can be obtained as accession codes (each of paired end reads available) SRR10971979, SRR10971978, SRR10971976, SRR10971975, SRR10971974, SRR10971973, SRR10971972, SRR10971971, SRR10971970, SRR10971969, and SRR10971977.

\section{Ethics approval and consent to participate}

Experimental methods were approved by the UCLA Chancellor's Animal Research Committee.

\section{Consent for publication}

All authors have consented to the publication of this manuscript.

\section{Competing interests}

All authors declare no competing interests.

\section{Author details}

${ }^{1}$ Department of Pediatrics and Human Development, College of Human Medicine, Michigan State University, Grand Rapids, MI 49503, USA.

2Department of Pharmacology and Toxicology, Michigan State University, East Lansing, MI 48824, USA. ${ }^{3}$ HudsonAlpha Institute for Biotechnology, Huntsville, AL 35806, USA. ${ }^{4}$ Johns Hopkins University, Baltimore, MD 21218, USA. ${ }^{5}$ Department of Integrative Biology \& Physiology, Laboratory of Neuroendocrinology of the Brain Research Institute, University of California, 610 Charles Young Drive South, Los Angeles, CA 90095, USA. ${ }^{6}$ Division of Mathematics and Science, Walsh University, North Canton, OH 44720, USA ${ }^{7}$ Department of Physiology, Medical College of Wisconsin, Milwaukee, WI 53226, USA.

Received: 5 February 2020 Accepted: 30 April 2020

Published online: 12 May 2020

\section{References}

1. Berta P, Hawkins JB, Sinclair AH, Taylor A, Griffiths BL, Goodfellow PN, et al. Genetic evidence equating SRY and the testis-determining factor. Nature. 1990;348:448-50.

2. Goodfellow PN, Lovell-Badge R. SRY and sex determination in mammals. Annu Rev Genet. 1993;27:71-92.

3. Capel B. Vertebrate sex determination: evolutionary plasticity of a fundamental switch. Nat Rev Genet. 2017;18:675-89.

4. Clepet C, Schater AJ, Sinclair AH, Palmer MS, Lovell-Badge R, Goodfellow PN. The human SRY transcript. Hum Mol Genet. 1993;2:2007-12.

5. Sekido R, Lovell-Badge R. Sex determination involves synergistic action of SRY and SF1 on a specific Sox9 enhancer. Nature. 2008:453:930-4.

6. Kashimada K, Koopman P. Sry: the master switch in mammalian sex determination. Dev Camb Engl. 2010;137:3921-30.

7. Salas-Cortés $L$, Jaubert $F$, Bono MR, Fellous M, Rosemblatt M. Expression of the human SRY protein during development in normal male gonadal and sex-reversed tissues. J Exp Zool. 2001;290:607-15.

8. Prokop JW, Deschepper CF. Chromosome Y genetic variants: impact in animal models and on human disease. Physiol Genomics. 2015; physiolgenomics.00074.2015.

9. Dewing P, Chiang CWK, Sinchak K, Sim H, Fernagut P-O, Kelly S, et al. Direct regulation of adult brain function by the male-specific factor SRY. Curr Biol. 2006;16:415-20.

10. Prokop JW, Underwood AC, Turner ME, Miller N, Pietrzak D, Scott S, et al. Analysis of Sry duplications on the Rattus norvegicus Y-chromosome. BMC Genomics. 2013;14:792.

11. Turner ME, Martin C, Martins AS, Dunmire J, Farkas J, Ely DL, et al. Genomic and expression analysis of multiple Sry loci from a single Rattus norvegicus Y chromosome. BMC Genet. 2007:8:11.

12. Bellott DW, Hughes JF, Skaletsky H, Brown LG, Pyntikova T, Cho T-J, et al. Mammalian Y chromosomes retain widely expressed dosage-sensitive regulators. Nature. 2014;508:494-9.

13. Prokop JW, Tsaih S-W, Faber AB, Boehme S, Underwood AC, Troyer S, et al. The phenotypic impact of the male-specific region of chromosome-Y in inbred mating: the role of genetic variants and gene duplications in multiple inbred rat strains. Biol Sex Differ. 2016:7:10.

14. Burgoyne PS, Arnold AP. A primer on the use of mouse models for identifying direct sex chromosome effects that cause sex differences in non-gonadal tissues. Biol Sex Differ. 2016;7:68.

15. De Vries GJ, Rissman EF, Simerly RB, Yang L-Y, Scordalakes EM, Auger CJ, et al. A model system for study of sex chromosome effects on sexually dimorphic neural and behavioral traits. J Neurosci Off J Soc Neurosci. 2002; 22:9005-14

16. Kaufman MH. The atlas of mouse development. Elsevier Science; 1992.

17. Hacker A, Capel B, Goodfellow P, Lovell-Badge R. Expression of Sry, the mouse sex determining gene. Dev Camb Engl. 1995;121:1603-14.

18. Patro R, Duggal G, Love MI, Irizarry RA, Kingsford C. Salmon provides fast and bias-aware quantification of transcript expression. Nat Methods. 2017; 14:417-9.

19. Zhou G, Soufan O, Ewald J, Hancock REW, Basu N, Xia J. NetworkAnalyst 3.0: a visual analytics platform for comprehensive gene expression profiling and meta-analysis. Nucleic Acids Res. 2019;47:W234-W241. 
20. Love Ml, Huber W, Anders S. Moderated estimation of fold change and dispersion for RNA-seq data with DESeq2. Genome Biol. 2014;15:550.

21. Szklarczyk D, Morris JH, Cook H, Kuhn M, Wyder S, Simonovic M, et al. The STRING database in 2017: quality-controlled protein-protein association networks, made broadly accessible. Nucleic Acids Res. 2017;45:D362-8.

22. Li H, Durbin R. Fast and accurate short read alignment with BurrowsWheeler transform. Bioinforma Oxf Engl. 2009;25:1754-60.

23. Okonechnikov K, Golosova O, Fursov M, UGENE team. Unipro UGENE: a unified bioinformatics toolkit. Bioinforma Oxf Engl. 2012;28:1166-7.

24. Clement TM, Anway MD, Uzumcu M, Skinner MK. Regulation of the gonadal transcriptome during sex determination and testis morphogenesis: comparative candidate genes. Reprod Camb Engl. 2007;134:455-72.

25. Desclozeaux M, Poulat F, de Santa BP, Capony JP, Turowski P, Jay P, et al. Phosphorylation of an N-terminal motif enhances DNA-binding activity of the human SRY protein. J Biol Chem. 1998;273:7988-95.

26. Zhao L, Ng ET, Davidson T-L, Longmuss E, Urschitz J, Elston M, et al. Structure-function analysis of mouse Sry reveals dual essential roles of the C-terminal polyglutamine tract in sex determination. Proc Natl Acad Sci U S A. 2014;111:11768-73.

27. Chen Y-S, Racca JD, Sequeira PW, Phillips NB, Weiss MA. Microsatelliteencoded domain in rodent Sry functions as a genetic capacitor to enable the rapid evolution of biological novelty. Proc Natl Acad Sci U S A. 2013; 110:E3061-70

28. Prokop JW, Watanabe IKM, Turner ME, Underwood AC, Martins AS, Milsted A. From rat to human: regulation of Renin-Angiotensin system genes by sry. Int J Hypertens. 2012;2012:724240

\section{Publisher's Note}

Springer Nature remains neutral with regard to jurisdictional claims in published maps and institutional affiliations.

Ready to submit your research? Choose BMC and benefit from:

- fast, convenient online submission

- thorough peer review by experienced researchers in your field

- rapid publication on acceptance

- support for research data, including large and complex data types

- gold Open Access which fosters wider collaboration and increased citations

- maximum visibility for your research: over $100 \mathrm{M}$ website views per year

At $\mathrm{BMC}$, research is always in progress.

Learn more biomedcentral.com/submissions 